\title{
PAINT FLAKES ON THE EXTERIOR AND IN THE WALL OF A RUBY- THROATED HUMMINGBIRD NEST
}

\author{
SPENCER G. SEALY, Department of Zoology, University of Manitoba, Winnipeg, MB \\ R3T 2N2
}

\section{Introduction}

The incorporation of lichen flakes on the outside of nests of many species of birds is well known in North America, especially among the hummingbirds, gnatcatchers and some pewees. ${ }^{3,8}$ Deception of visual predators has been the function most widely suggested for this. ${ }^{1,3,15,18}$ Welty (p. 283) assumed that "such a covering, which often matches the surroundings, helps make the nest less conspicuous". ${ }^{18}$ The nest of the Long-tailed Tit, in Europe, was described by Perrins (p. 73) as "...beautifully camouflaged [with greyish lichens], especially against a tree trunk", 11 and Nicholas and Elsie Collias (p. 148) suggested that lichen flakes act as "...camouflage of the exterior of the nest to resemble the immediate environment," especially as many of these nests are saddled on branches and look like knots. ${ }^{3}$

Although some workers have acknowledged that lichens, other plant parts or white spider cocoons attached to the exterior of nests may have some utility, others have used terms such as "adornments" and "decorations" to describe them. . $^{2,15,18}$ Alexander Skutch, for example, stated (p. 104) "...we are tempted to regard them as adornments and apply the term 'decorators' to the birds who so embellish their homes." 15 It is currently believed, however, that these materials are more than just decorations and in some way enhance the reproductive success of the nesting birds.

Two hypotheses have been presented to explain the function of lichen flakes and white spider cocoons attached to the external surfaces of bird nests: the branch-matching hypothesis (masquerade) ${ }^{3}$ and lightreflecting hypothesis (crypsis). ${ }^{5}$ In the former hypothesis, a nest is considered to resemble a part of the branch to which it is attached, such as a knot, whereas in the latter, following Endler, ${ }^{4}$ the nest reflects light and dissolves into the background beyond the site of attachment. Hansell ${ }^{6}$ tested these hypotheses by examining nests and their positions on the supporting branches, and the extent of lichens covering the branches. His observations supported the crypsis hypothesis, as the nests are concealed because light that falls on them is reflected and they dissolve into the background. The masquerade hypothesis was not supported because most nests were wider than the branches to which they were attached and these branches tended not to be covered with lichens. As little is known about the predators on the contents of such nests, the hypotheses proposed to explain the adaptive significance of this use of lichen flakes have been tested only indirectly.

\section{Observations}

Here I report on flakes of paint applied to the outside and as part of the body of the nest of a Ruby-throated Hummingbird. In August 1984, Luke Maynard brought the empty hummingbird nest in its original position on a branch to the University of Manitoba Zoology Museum (UMZM 2851). The nest was found in St. Malo Provincial Park, Manitoba, about $70 \mathrm{~km}$ south of Winnipeg, and has flakes of green paint, most dark green (corresponding to "dark green," no. 262, in Smithe ${ }^{16}$ ) with some light green ("emerald green," no. 163), covering nearly its entire outer surface (Fig.1). Maynard had not noticed whether the green paint might have come from a nearby building or bench. A few lichen thalli were on the outside of the nest where paint flakes were absent. I did not dissect the nest, however, at least three flakes of paint can be seen incorporated into the plant down used 

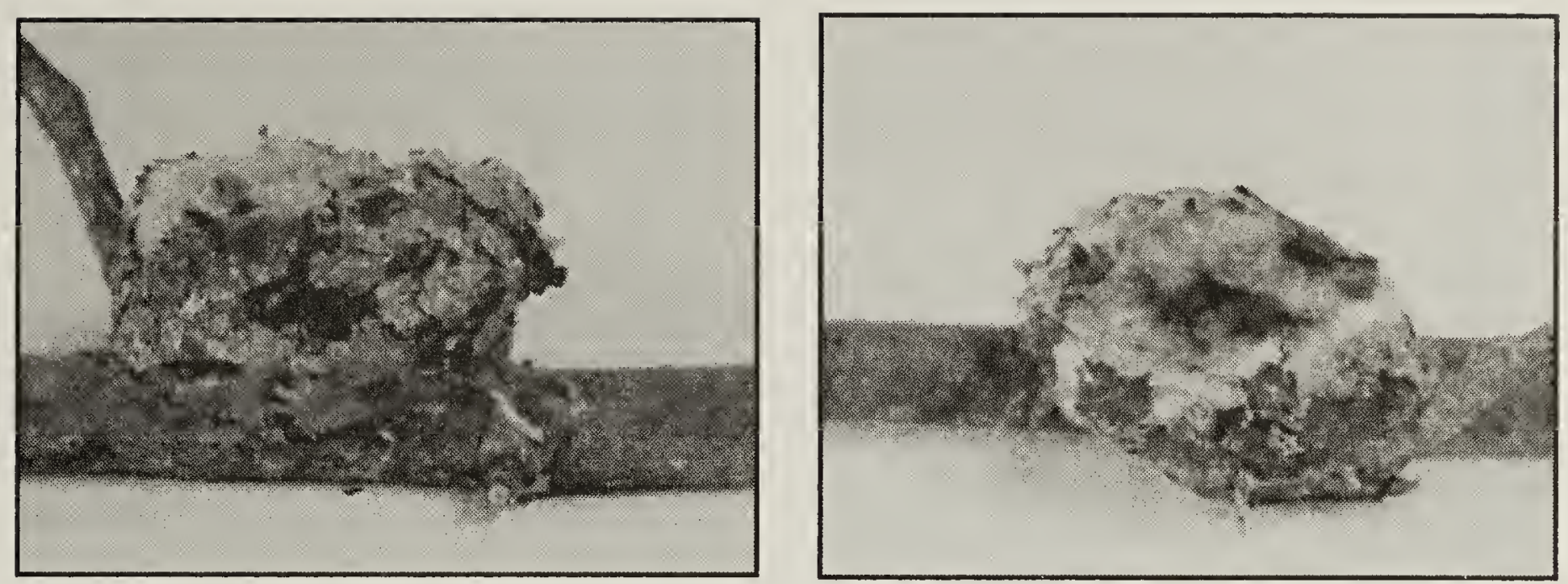

Two views of a Ruby-throated Hummingbird nest (UMZM 2851) showing paint flakes on the exterior.

to construct the body of the nest. The paint flakes are attached to the nest and branch with strands of spider silk, which are clearly visible under a dissecting microscope. The $35-\mathrm{cm}$ portion of the branch collected with the nest was devoid of lichens, except for a small patch about $45 \mathrm{~mm}$ from the nest. The nest was also wider than the branch onto which it was saddled ( $38 \mathrm{~mm}$ versus $12 \mathrm{~mm}$, respectively); thus, it did not resemble a knot. These attributes support the predictions of the crypsis hypothesis.

\section{Discussion}

This is not the first record of paint flakes used on the outside of a Ruby-throated Hummingbird nest. On the front cover of Blue Jay (Volume 50, June 1992) there is a photograph by the late Doug Gilroy of a female Ruby-throated Hummingbird incubating eggs or brooding young in a nest at Regina Beach, Saskatchewan. Four or five flakes of light green paint are visible on the outside of the nest, whereas lichens were attached to the rest of its surface. In another species, Anna's Hummingbird, two nests from California had external layers composed of flakes of paint instead of the usual lichen flakes, with white flakes on one nest and sky blue flakes among white flakes on the other. ${ }^{6}$ Man-made materials other than paint, such as white paper, newsprint and polystyrene also have been used on the exterior of nests. ${ }^{6,7}$ While examining nests in the collections of the United States National Museum, Mike Hansell (pers. comm.) noted newspaper fragments among the pieces of lichen on the outside of 4 of 19 Common Bushtit nests. One of these nests was collected in 1892, in San Diego, California, which indicates this has been going on for more than 100 years!

Other possible functions for the incorporation of lichen flakes or other materials on the exterior of nests require testing. Upon initially noticing the paint in the wall as well as on the outside of nest UMZM 2851, I wondered whether flakes, lichens or otherwise, provide support for the nests, even when placed only on their outsides, but especially when also incorporated into their walls. In three other Ruby-throated Hummingbird nests, large lichen thalli completely covered the outside of one nest (UMZM 2848) and tiny pieces of lichen were "sprinkled" on the outsides of the others (UMZM 2849, 2850), but no lichen was visible in the walls of any of them. A fourth nest (UMZM 2862) had chips of bark attached to the outside. These observations suggest Ruby-throated Hummingbirds use whatever is available nearby to cover the exterior of their nests, or they may place their nests near sources of material appropriate for use on their outsides.

Others have suggested lichens may minimize soaking of the plant down in the structural layer, by shedding water when it rains or humidity is high, thus protecting nests against disintegration. ${ }^{6.17} \mathrm{It}$ is evident from photographs of nests of several other hummingbirds, particularly tropical species, that nests constructed with materials other than plant down generally lacked lichens or only a few were along the rims of the nests. ${ }^{10,13,14,17}$ Tests are needed to determine 
whether lichens support and/or protect the physical integrity of the nests, but at the same time possibly rendering nests less conspicuous to predators.

It has also been suggested that lichens play a role in nest sanitation by controlling the number of parasites in nests. ${ }^{9}$ However, whereas the other materials, such as green leaves, that apparently do control parasitic arthropods, are used to line nests, ${ }^{2}$ a different mechanism surely would exist in this case because the lichens are not used in the lining of hummingbird nests. In a different vein, Hansell speculated that lichens reflect radiation and, hence, possibly play a role in controlling the temperature of the nest. ${ }^{7,8}$ This might be in conjunction with variation in the materials used to construct nests and the degree of insulation, ${ }^{17}$ including the type and density of lichen flakes on the outside. Clearly, not all of these ideas and hypotheses are mutually exclusive and it may turn out, with testing, that more than one is supported.

\section{Acknowledgements}

I thank Luke Maynard for donating the hummingbird nest with the paint flakes on its exterior to the University of Manitoba. Personnel of the Delta Waterfowl Foundation salvaged one of the other hummingbird nests examined and Robyn and Todd Underwood found another nest. Jolanta Miadlikowska kindly provided a copy of her paper published in the Polish literature. Bruce Ford examined the plant materials in the linings and on the exterior of some of the nests. Robert Barrow prepared the photographs. Mike Hansell read the manuscript, offered several useful suggestions, and provided information on the use of newspaper fragments in Common Bushtit nests.

1. ALCORN, G.D. 1991. Birds and their Young. Stackpole, Harrisburg, PA.

2. CLARK, L., and J.R. MASON. 1985. Use of nest material as insecticidal and anti-pathogenic agents by the European Starling. Oecologia 67: 169-176.

3. COLliAS, N.E., and E.C. COLLIAS. 1984. Nest Building and Bird Behavior. Princeton University Press, Princeton, NJ.
4. ENDLER, J.A. 1990. On the measurement and classification of colour in studies of animal colour pattern. Biological Journal of the Linnean Society 41: 315-352.

5. HANSELL, M.H. 1993. Secondhand silk. Natural History 102: 40-46.

6. HANSELL, M.H. 1996. The function of lichen flakes and white spider cocoons on the outer surface of birds' nests. Journal of Natural History 30: 303-311.

7. HANSELL, M. 2000. Bird Nests and Construction Behaviour. Cambridge University Press, Cambridge, UK.

8. HANSELL, M.H., and D.C. DEEMING. 2002. Location, structure and function of incubation sites. In: D.C. Deeming (ed.). Avian Incubation: Behaviour, Environment, and Evolution. Oxford University Press, Oxford. Pp. 8-27.

9. MIADLIKOWSKA, J. 1990. Czy zwierzeta "lubia" porosty? [Do animals "like" lichens?] Wiadomosci Ekologiczne 36: 203-212.

10. ONIKI, Y. 1970. Nesting behavior of Reddish Hermits (Phaethornis ruber) and occurrence of wasp cells in nests. Auk 87: 720-728.

11. PERRINS, C. 1979. British Tits. Collins, New Naturalist Series, London, UK.

12. ROBINSON, T.R., R.R. SARGENT, and M.B. SARGENT. 1995. Ruby-throated Hummingbird (Archilochus colubris). In: Poole, A. and F. Gill (eds.). The Birds of North America, No. 204. The Birds of North America, Inc., Philadelphia, PA.

13. ROWLEY, J.S. 1966. Breeding records of birds of the Sierra Madre del Sur, Oaxaca, Mexico. Proceedings of the Western Foundation of Vertebrate Zoology 1: 106-204.

14. ROWLEY, J.S. 1984. Breeding records of land birds in Oaxaca, Mexico. Proceedings of the Western Foundation of Vertebrate Zoology 2: 76-221.

15. SKUTCH, A.F. 1976. Parent Birds and their Young. University of Texas Press, Austin, TX.

16. SMITHE, F.B. 1974. Naturalist's Color Guide. American Museum of Natural History, New York, NY.

17. WAGNER, H.O. 1955. Einfluß der Poikilothermie bei Kolibris auf ihre Brutbiologie. [Influence of poikilothermy on the breeding biology of hummingbirds.] Journal für Ornithologie 96: 361 368.

18. WELTY, J.C. 1979. The Life of Birds. Saunders College Publishing, Philadelphia, PA. 